\title{
Stability-Indicating HPTLC-Densitometric Method for Estimation of Dorzolamide Hydrochloride in Eye Drops
}

\author{
S. S. Havele ${ }^{1}$ and S. R. Dhaneshwar ${ }^{2}$ \\ ${ }^{1}$ Department of Pharmaceutical Chemistry, Poona College of Pharmacy, Bharati Vidyapeeth University, \\ Maharashtra, Pune 411038, India \\ ${ }^{2}$ Department of Pharmaceutical Chemistry, College of Pharmaceutical Sciences, RAK Medical \& Health Sciences University, \\ P.O. Box 11172, Ras Al-Khaimah, UAE
}

Correspondence should be addressed to S. S. Havele, shwetahavele@gmail.com

Received 26 March 2012; Accepted 7 May 2012

Academic Editors: J. N. Latosinska and K. Ohyama

Copyright ( $) 2012$ S. S. Havele and S. R. Dhaneshwar. This is an open access article distributed under the Creative Commons Attribution License, which permits unrestricted use, distribution, and reproduction in any medium, provided the original work is properly cited.

The present study describes the degradation of dorzolamide $\mathrm{HCl}$ under different International Conference on Harmonization prescribed stress conditions (hydrolysis, oxidation, thermolysis, and photolysis) and application of a specific and selective stabilityindicating chromatography assay. HPTLC was done on silica Gel $60 \mathrm{~F}_{254}$ TLC plate using chloroform: methanol in the ratio of 9.0:1.0 (v/v) as mobile phase and detection at $253 \mathrm{~nm}$.

\section{Introduction}

Dorzolamide hydrochloride (DORZO), (4S,6S)-4-ethylamino-5,6-dihydro-6-methyl-4H-thieno(2,3-b)thiopyran2-sulfonamide 7,7-dioxide monohydrochloride (Figure 1), is a carbonic anhydrase inhibitor used in eye drops to treat increased pressure in the eye caused by open-angle glaucoma and to treat a condition called hypertension of the eye [1].

The literature review reveals that several methods have been reported for the estimation of DORZO in biological fluids [2-5], and there are some methods reported by HPLC [6-9], spectroscopy $[10,11]$, and capillary electrophoresis [12], and there are some methods reported for estimation of DORZO in pharmaceutical formulation [13-15]. According to current good manufacturing practices, all drugs must be tested with a stability-indicating assay method before release. So far, to our present knowledge, no stability-indicating HPTLC assay method for the determination of DORZO is available in the literature.

Now a days, HPTLC is rapidly becoming a routine analytical technique due to its advantages of low operating costs, need for minimum sample preparation, and high sample throughput. The major advantage of HPTLC is that several samples can be run simultaneously using a small quantity of mobile phase unlike HPLC—-thus reducing the analysis time and cost per analysis.

It was felt necessary to develop stability-indicating HPTLC method for the determination of DORZO as bulk drug and pharmaceutical dosage form and separate the drugs from the degradation products under the ICH-suggested conditions. Therefore, the aim of the present study was to develop and validate stability-indicating HPTLC assay methods for DORZO as bulk drug and in pharmaceutical dosage form as per International Conference on Harmonisation guidelines [16-19].

\section{Experimental}

2.1. Drug and Reagents. Pharmaceutical grade DORZO working standard was obtained as generous gift from FDC Ltd., Mumbai, India. The eye drop sample (Ocudor eye drops, manufactured by Lumina (FDC Limited)) was obtained commercially. The DORZO was labeled (per $1 \mathrm{~mL}$ ) as $22.26 \mathrm{mg}$. All chemicals and reagents were of analytical grade and were purchased from Merck Chemicals, Mumbai, India. 


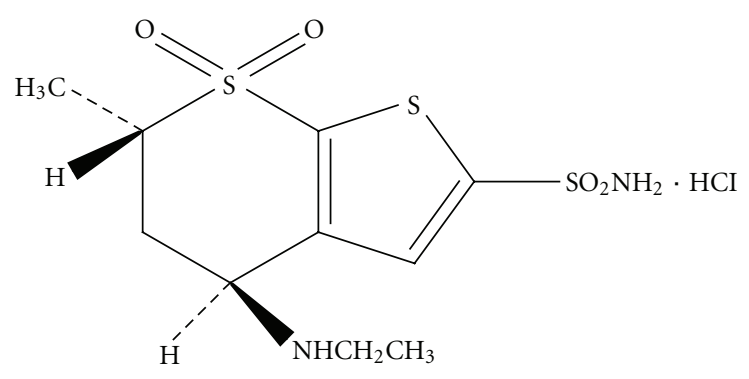

FIGURE 1: Chemical structure of dorzolamide hydrochloride.

\subsection{Instrumentation}

2.2.1. For Stress Study. High-precision heating mantel (Remi, India) capable of controlling the temperature with in $\pm 1{ }^{\circ} \mathrm{C}$ was used for generating hydrolytic degradation products. The thermal degradation study was performed using a high-precision hot air oven (Kumar Scientific Works, Pune, India) capable of controlling the temperature within $\pm 2{ }^{\circ} \mathrm{C}$. Photodegradation was carried out in a photostability chamber (Thermolab, Scientific Equipment Pvt. Ltd.) equipped with lighting system to comply with $\mathrm{ICH}$ guideline for photostability condition with white fluorescent exposure of 1.2 million lux hours and integrated near ultraviolet energy exposure of 200 watts hours/sq.mts (option 2 of the $\mathrm{ICH}$ guideline Q1B). At any given time, UV energy and visible illumination were tested using a calibrated lux meter (Lutron, LX-101A).

2.3. Chromatographic Conditions. The HPTLC system consisted of a Camag Linomat 5 semiautomatic spotting device (Camag, Muttenz, Switzerland), a Camag twin-trough chamber $(10 \mathrm{~cm} \times 10 \mathrm{~cm})$, Camag winCATS software 1.4.4.6337 and a $100 \mu \mathrm{L}$ Hamilton syringe. Sample application was done on precoated silica gel $60 \mathrm{~F}_{254}$ TLC plates $(10 \mathrm{~cm}$ $\times 10 \mathrm{~cm})$. TLC plates were prewashed with methanol and activated at $80^{\circ} \mathrm{C}$ for $5 \mathrm{~min}$ prior to the sample application. Densitometric analysis was carried out utilizing Camag TLC scanner 3.

2.4. Preparation of Standard Stock Solutions. A standard stock solution of $1 \mathrm{mg} / \mathrm{mL}$ DORZO was prepared in water.

Working standard solutions were prepared by dilution of the stock solution with water to reach a concentration range of $100-500 \mathrm{ng} / \mathrm{spot}$.

2.5. Preparation of Analytical Samples. $1 \mathrm{~mL}$ of the Ocudor eye drop was transferred into a $100 \mathrm{~mL}$ volumetric flask adjusted up to $100 \mathrm{~mL}$ with water and sonicated for $15 \mathrm{~min}$. The resulting solutions (sample solutions) were then analyzed by HPTLC after filtration through Whatman filter paper 41 .

2.6. Stress Degradation Studies. A standard stock solution was used for stress degradation to provide an indication of the stability-indicating property and specificity of the method. In all degradation studies, the average peak area of DORZO after application of six replicates was obtained.

2.6.1. Hydrolysis. Acidic decomposition studies were performed by heating the drug solution under reflux at $60^{\circ} \mathrm{C}$ for $2 \mathrm{~h}$ with $1 \mathrm{M}$ hydrochloric acid. Studies under alkaline hydrolysis were performed in $0.2 \mathrm{M}$ sodium hydroxide solution under reflux at $60^{\circ} \mathrm{C}$ for $4.5 \mathrm{~h}$. The resulting solutions were applied to the plates for HPTLC. The degradation behavior of drug in neutral conditions was studied by mixing $5 \mathrm{~mL}$ of a standard stock solution $(1 \mathrm{mg} / \mathrm{mL})$ with $5 \mathrm{~mL}$ double-distilled water and heated at $80^{\circ} \mathrm{C}$ for 5 days, and subsequently for 10 days.

2.6.2. Hydrogen Peroxide-Induced Degradation. To study hydrogen peroxide-induced degradation, the drug solution was treated with $6 \%$ hydrogen peroxide at room temperature for $72 \mathrm{~h}$. The solution was then heated in a boiling water bath for 10 min to completely remove excess hydrogen peroxide.

2.6.3. Photolysis. Photodegradation studies were carried out according to option 2 of $\mathrm{Q} 1 \mathrm{~B}$ in $\mathrm{ICH}$ guidelines. The stock solution as well as solid drug were exposed to light for an overall illumination of 1.2 million lux/h and an integrated near ultraviolet energy of $200 \mathrm{~W} \mathrm{hm}^{-2}$ for 4 days by fluorescent near-UV and cool white light.

2.6.4. Thermolysis. $10 \mathrm{mg}$ standard drug in solid form was placed in an oven at $50^{\circ} \mathrm{C}$ for 30 days to study dry heat degradation. To study wet heat degradation, the drug was kept in a humidity chamber at $50^{\circ} \mathrm{C}, 75 \%$ relative humidity for 3 months.

2.7. Optimization of the Method. The HPTLC procedure was optimized to establish a stability-indicating assay. Both pure and degraded drug solutions were applied to HPTLC plates and chromatographed with different mobile phases.

2.8. Analytical Method Validation. The developed chromatographic method was validated for linearity, precision, accuracy, sensitivity, robustness, and system suitability.

2.8.1. Linearity and Range. From the working standard solution, five different concentrations (100-500 ng/spot) were spotted on the TLC plate.

The peak areas were plotted against the corresponding concentrations to obtain the calibration graphs.

2.8.2. Precision. The precision of the method was verified by repeatability and intermediate precision studies. Repeatability studies were performed by analysis of three different concentrations of 100, 300, and $500 \mathrm{ng} / \mathrm{spot}$ six times on the same day. The intermediate precision of the method was checked by repeating studies on two different days.

2.8.3. Sensitivity. Sensitivity was determined by establishing the limit of detection (LOD) and limit of quantitation 
TABLE 1: Linear regression data for the calibration curves ${ }^{\mathrm{a}}$.

\begin{tabular}{lcc}
\hline \multicolumn{2}{c}{ Parameters } & DORZO \\
\hline Linearity (ng/spot) & & $100-500$ \\
$y=\mathrm{A}+\mathrm{B} x$ & $\mathrm{~A}$ & 2.073 \\
& $\mathrm{~B}$ & 56.78 \\
$r^{2}$ & & 0.999 \\
\hline
\end{tabular}

$n=6 ; r^{2}=$ coefficient of correlation.

TABLE 2: Repeatability and intermediate day precision of methods ${ }^{\mathrm{a}}$.

\begin{tabular}{lccc}
\hline \multicolumn{2}{c}{ Repeatability } & \multicolumn{2}{c}{ Intermediate } \\
\hline Mean\% assay & \% R.S.D. & Mean\% assay & \% R.S.D. \\
100.3 & 0.08 & 99.75 & 1.68 \\
\hline
\end{tabular}

${ }^{a} n=6,(100,300,500 \mathrm{ng} / \mathrm{spot})$.

(LOQ) which represent the concentration of the analyte that would yield signal-to-noise ratios of 3 for LOD and 10 for LOQ, respectively. The LOD and LOQ were determined by measuring the magnitude of analytical background by spotting a blank and calculating the signal-to-noise ratio for DORZO by spotting a series of solutions until the $\mathrm{S} / \mathrm{N}$ ratio 3 was obtained for the LOD and 10 for the LOQ.

2.8.4. Robustness. The robustness was studied by evaluating the effect of small but deliberate variations in the chromatographic conditions. The parameters which included change in mobile-phase composition like chloroform:methanol in the ratio of $(8.9: 1.0 \mathrm{v} / \mathrm{v}),(9.0: 0.9 \mathrm{v} / \mathrm{v}),(9.1: 1.0 \mathrm{v} / \mathrm{v})$, and $(9.0: 1.1 \mathrm{v} / \mathrm{v})$ were varied and densitograms were run. The amount of mobile phase was varied over the range of $\pm 0.1 \%$. The plates were prewashed by methanol and activated at $110^{\circ} \mathrm{C}$ for 4,5 , and $6 \mathrm{~min}$, respectively, prior to chromatography. Time from spotting to chromatography and from chromatography to scanning was varied from $\pm 10 \mathrm{~min}$. Robustness of the method was done at a concentration level of $400 \mathrm{ng} / \mathrm{spot}$. Robustness of the method was done at three different concentration levels $(100,300,500 \mathrm{ng} / \mathrm{spot})$. These chromatographic variations were evaluated for resolution between DORZO and degradation products.

2.8.5. Specificity. The specificity of the method was determined by analysis of drug standard and test samples. Identification of the DORZO spot from the samples was confirmed by comparison of its $R_{f}$ and spectrum with those from a standard. In addition, the peak purity of DORZO was assessed by acquiring spectra at the peak-start (S), peak-apex $(\mathrm{M})$, and peak-end (E) positions of the spot and calculating the correlation between them. The specificity of the method was also checked by separation of DORZO in the presence of its degradation products.

2.8.6. Accuracy. Accuracy of the method was carried out by applying the method to preanalyzed drug sample to which known amounts of DORZO standard powder corresponding to 80,100 , and $120 \%$ of label claim had been added (standard addition method) mixed, and the powder was extracted
Track 1, ID:

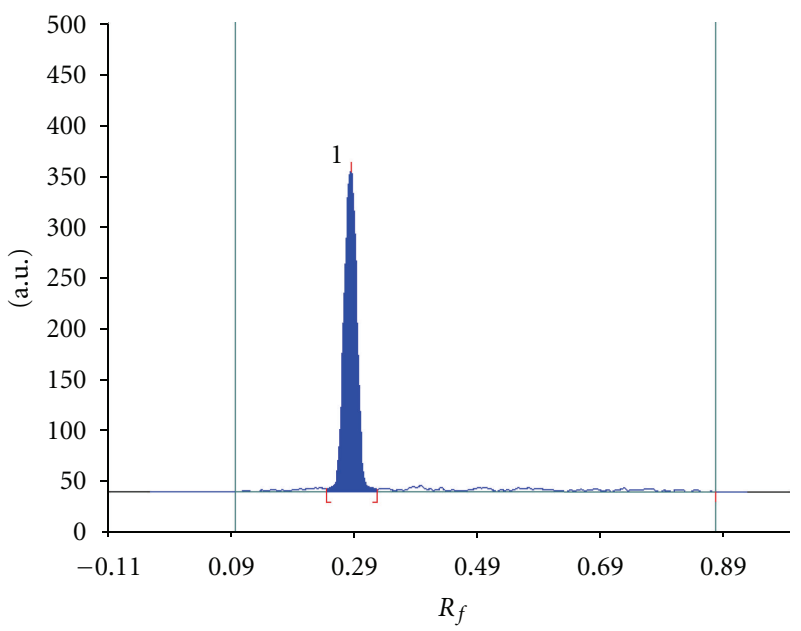

Figure 2: Densitogram of standard dorzolamide hydrochloride (700 ng/spot).

and analyzed by running chromatograms in optimized mobile phase. These mixtures were analyzed by the proposed method. The experiment was performed in triplicate, and recovery (\%) was calculated.

2.8.7. Analysis of Eye Drops. The contents of drug in eye drops were determined by the proposed method using the calibration curve.

2.8.8. Solution Stability. The solution stability of DORZO was carried out by leaving the test solution in tightly capped volumetric flasks at room temperature for $24 \mathrm{~h}$ and assayed at $6 \mathrm{~h}$ interval, against the freshly prepared standard solution. The \% RSD of assay of DORZO was calculated for the study period during solution stability experiments.

\section{Results and Discussion}

In this work, analytical HPTLC method with UV detection was developed and validated for the determination of DORZO in bulk drug and pharmaceutical formulations. To prove the method was stability indicating, the drug was assayed in presence of its degradation products obtained under stress conditions like acidic, basic, neutral, and oxidative conditions, photodegradation, and thermal degradation.

3.1. Method Development and Optimization. The HPTLC procedure was optimized with a view to develop a suitable HPTLC method for the analysis of DORZO and its degradation products. Several trials were made by using different solvent systems containing nonpolar solvents and relatively polar solvents. Initially, chloroform and methanol were tried in different ratios. Finally, the mobile phase consisting chloroform:methanol $(9.0: 1.0 \mathrm{v} / \mathrm{v})$ gave better resolution and sharper peaks with $R_{f}$ values of $0.28 \pm$ 0.05 (Figure 2). Well-defined spots were obtained when the 
TABLE 3: Robustness testing.

\begin{tabular}{lcc}
\hline Parameters & SD of peak area & $\%$ RSD \\
\hline Mobile-phase composition $( \pm 0.1 \mathrm{~mL})$ & 28.3 & 0.91 \\
Amount of mobile phase $( \pm 5 \%)$ & 41 & 0.33 \\
Plate pretreatment $(4,5,6 \mathrm{~min})$ & 1.2 & 0.02 \\
Time from spotting to chromatography $(+10 \mathrm{~min})$ & 0.5 & 0.07 \\
Time from chromatography to scanning $(+10 \mathrm{~min})$ & 0.08 & 0.01 \\
\hline
\end{tabular}

TABLE 4: Stability of drugs in sample solutions ${ }^{\mathrm{a}}$.

\begin{tabular}{lcc}
\hline Time of analysis (hrs) & SD of area & \% RSD of area \\
\hline 6 & 102 & 1.30 \\
12 & 381 & 0.91 \\
18 & 91 & 0.33 \\
24 & 62 & 1.75 \\
\hline
\end{tabular}

${ }^{\mathrm{a}}(n=6)$ Average of three concentrations (100, 300, and $\left.500 \mathrm{ng} / \mathrm{spot}\right)$.

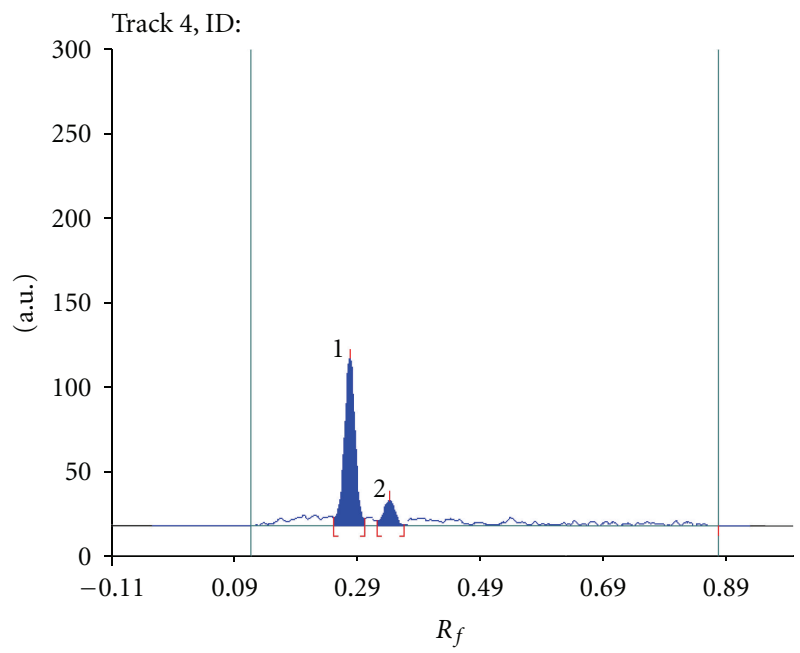

FIgURE 3: Densitogram of the acid degradation product $300 \mathrm{ng} / \mathrm{spot}$; condition: $1 \mathrm{M} \mathrm{HCl}$ at room temperature for $2 \mathrm{~h}$; peak 1 (dorzolamide hydrochloride, $R_{f}: 0.29$ ), peak 2 (degraded, $\left.R_{f}: 0.33\right)$.

chamber was saturated with the mobile phase for $20 \mathrm{~min}$. The analytical wavelength of $253 \mathrm{~nm}$ was chosen on the basis of the absorption spectrum recorded in the range of 200$400 \mathrm{~nm}$.

\subsection{Detection of Degradation Products}

3.2.1. Hydrolysis. The drug solution refluxed with $1 \mathrm{M} \mathrm{HCl}$ at $60^{\circ} \mathrm{C}$ for $2 \mathrm{~h}$. Degradation product was formed with $R_{f}$ of 0.33 in HPTLC (Figure 3 ). The drug solution in $0.2 \mathrm{M}$ sodium hydroxide solution under reflux at $60^{\circ} \mathrm{C}$ showed degradation for $4.5 \mathrm{~h}$ associated with a major degradation product at $R_{f}$ of 0.32 (Figure 4), DORZO under neutral hydrolysis did not show degradants as the peak area



FIGURE 4: Densitogram of base-treated dorzolamide hydrochloride $300 \mathrm{ng} / \mathrm{spot}$; condition: $0.2 \mathrm{M} \mathrm{NaOH}$ at $60^{\circ} \mathrm{C}$ for $4.5 \mathrm{~h}$; peak 1 (dorzolamide hydrochloride, $R_{f}: 0.28$ ), peak 2 (degraded, $R_{f}: 0.32$ ).

remained constant which indicated drug stability under the conditions investigated.

3.2.2. Oxidation. The drug was unstable to oxidative degradation; $27.65 \%$ degradation was observed when it was reacted with $6 \%$ hydrogen peroxide at room temperature for $72 \mathrm{~h}$. The chromatogram had degradation product peak at $R_{f}$ of 0.66 (Figure 5 ).

3.2.3. Dry and Wet Heat Degradation Product. There was no significant degradation of solid DORZO on exposure to dry heat at $50^{\circ} \mathrm{C}$ for 2 months, which indicated that drug was stable against thermal stress. However, the exposure of drug to $40^{\circ} \mathrm{C} / 75 \% \mathrm{RH}$ for 3 months resulted in slight degradation (less than $5 \%$ ).

3.2.4. Photolysis. DORZO was degraded in photochemical degradation after exposing drug to a combination of white fluorescent and integrated near ultraviolet energy at 1.2 million lux hours and 200 watts hours/sq.mts, respectively, for 4 days forming single major degradation product at $R_{f}$ of 0.67 in HPTLC (Figure 6 ). The data of summary of degradation are listed in Table 8. 
TABle 5: Recovery studies ${ }^{\mathrm{a}}$.

\begin{tabular}{|c|c|c|c|c|}
\hline Label claim & Amount of drug added (\%) & Total amount of drug present ng/spot & Amount found ng/spot & \% Recovery \\
\hline \multirow{3}{*}{$22.26 \mathrm{mg} / \mathrm{ml}$} & 80 & 400.68 & 399.75 & 99.77 \\
\hline & 100 & 445.20 & 442.79 & 99.46 \\
\hline & 120 & 489.72 & 485.01 & 99.04 \\
\hline
\end{tabular}

TABLE 6: Applicability of the HPTLC method for the analysis of the pharmaceutical formulations.

\begin{tabular}{lccc}
\hline Label claim $(\mathrm{mg} / \mathrm{ml})$ & \% RSD & Drug content (\%) & \% R.S.D. \\
\hline 22.26 & 0.05 & 99.92 & 0.09 \\
\hline
\end{tabular}

TABLE 7: Summary of validation parameters.

\begin{tabular}{lc}
\hline Parameter & DORZO \\
\hline Linearity range (ng/spot) & $100-500$ \\
Correlation coefficient & $0.9992 \pm 0.04$ \\
Limit of detection (ng/spot) & 30 \\
Limit of quantitation (ng/spot) & 95 \\
Recovery ( $n=6)$ & 99.42 \\
Precision (\% R.S.D.) & \\
$\quad$ Repeatability & 0.08 \\
$\quad$ Intermediate & 1.68 \\
Robustness & Robust \\
Specificity & Specific \\
\hline
\end{tabular}

\subsection{Validation of the Chromatographic Method}

3.3.1. Linearity. Linearity was evaluated by analysis of working standard solutions of DORZO of five different concentrations. The range of linearity was from 100 to $500 \mathrm{ng} / \mathrm{spot}$. The regression data obtained are represented in Table 1 . The result shows that within the concentration range mentioned above, there was an excellent correlation between peak area and concentration of each drug.

The drug response was linear $\left(r^{2}=0.999\right)$ over the concentration range between 100 to $500 \mathrm{ng} /$ spot. The values of slope, intercept, and correlation coefficient were 2.073, 56.78 , and 0.999 respectively.

3.3.2. Precision. The results of the repeatability and intermediate precision experiments are shown in Table 2. The developed methods were found to be precise, with RSD values for repeatability and intermediate precision $<2 \%$, as recommended by ICH guidelines. Separation of the drugs was found to be similar when analysis was performed on different chromatographic systems on different days.

3.3.3. $L O D$ and $L O Q$. The $L O D$ and $L O Q$ values were found to be 30 and $95 \mathrm{ng} / \mathrm{spot}$.

3.3.4. Specificity. The correlations between spectra acquired at the peak-start $(\mathrm{S})$, peak-apex $(\mathrm{M})$, and peak-end (E) positions of a spot were: $r(\mathrm{~S}, \mathrm{M})=0.9992$ and $(\mathrm{M}, \mathrm{E})=0.9995$. Good correlation $(r=0.9945)$ was also obtained between
Track 4, ID:

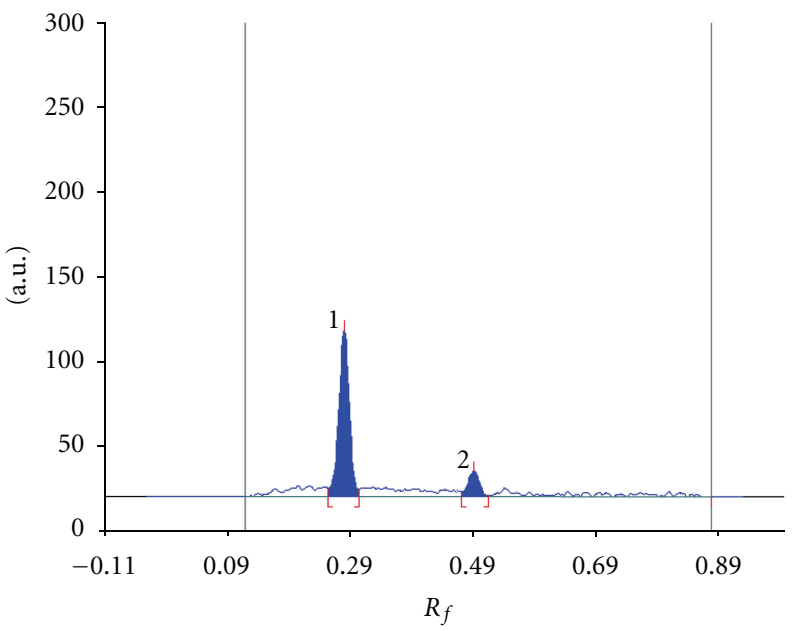

Figure 5: Densitogram of $\mathrm{H}_{2} \mathrm{O}_{2}$ (6\%, reflux for $\left.72 \mathrm{~min}\right)$ treated dorzolamide hydrochloride $700 \mathrm{ng} / \mathrm{spot}$; peak 1 (degraded, $R_{f}$ : 0.28 ) and peak 2 (dorzolamide hydrochloride, $R_{f}: 0.66$ ).

Track 3, ID:

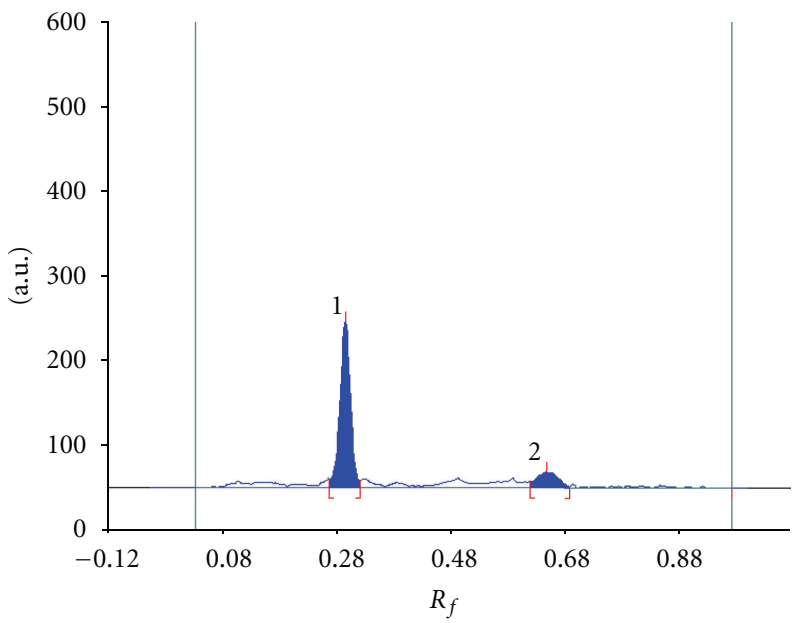

FIgure 6: Densitogram of photodegradation (4 days) treated dorzolamide hydrochloride $700 \mathrm{ng} / \mathrm{spot}$; peak 1 (degraded, $R_{f}$ : 0.26 ) and peak 2 (dorzolamide hydrochloride, $R_{f} 0.64$ ).

standard and sample spectra of DORZO. The specificity of the method is also apparent in Figure 3-6. In these figures, DORZO is completely separated from its degradation products. The peaks are sharp and clearly separated at baseline. 
TABLE 8: Summary of stress study.

\begin{tabular}{|c|c|c|c|c|}
\hline \multirow{2}{*}{ Parameter } & \multicolumn{4}{|c|}{ Condition } \\
\hline & Acid $1 \mathrm{M} \mathrm{HCl}, \mathrm{ref}^{\mathrm{a}}\left(60^{\circ} \mathrm{C}\right)$ & Base $0.2 \mathrm{M} \mathrm{NaOH}, \operatorname{ref}^{\mathrm{a}}\left(60^{\circ} \mathrm{C}\right)$ & $\mathrm{H}_{2} \mathrm{O}_{2} 6 \%(\mathrm{w} / \mathrm{v})$ & UV light \\
\hline Time (hrs) & 2 & 4.5 & 72 & 96 \\
\hline Assay of active substance $\%$ & 88.02 & 77.96 & 72.31 & 84.95 \\
\hline Mass balance & 99.99 & 99.92 & 99.98 & 99.96 \\
\hline Degradation (\%) & 22.25 & 18.53 & 22.88 & 0.80 \\
\hline$R_{f}$ of major degradation product & 0.33 & 0.32 & 0.66 & 0.64 \\
\hline
\end{tabular}

${ }^{a}$ Refluxed for $60^{\circ} \mathrm{C}$.

3.3.5. Robustness of the Method. The standard deviation of peak areas was calculated for each change of condition, and RSD was found to be $<2 \%$. Such low values of the RSD are indicative of the robustness of the method (Table 3 ).

3.3.6. Solution Stability Studies. No additional peak was found in the densitogram of sample from solution stability. The results from solution stability experiments confirmed that standard solutions were stable up to $24 \mathrm{~h}$ for assay and related substances analysis as shown in Table 4.

3.3.7. Recovery Studies. Good recoveries of the DORZO were obtained at various added concentrations for Ocudor eye drops as shown in Table 5.

3.3.8. Analysis of a Commercial Formulation. Experimental results of the amount of DORZO in eye drops, expressed as a percentage of label claims, were in good agreement with the label claims thereby suggesting that there is no interference from any of the excipients which are normally present in eye drops. Commercially available eye drops were analyzed using the proposed procedure in Table 6 .

The data of summary of validation parameters are listed in Table 7.

\section{Conclusion}

Stability-indicating HPTLC method was developed for DORZO and validated as per ICH guidelines. In this study, intrinsic stability of DORZO was established using various ICH-recommended stress conditions. The drug as such was very stable in solid form and in solution. In the latter case, unknown decomposition products were formed under stress condition. The drug was found to degrade more extensively in alkaline condition than in acidic condition. Mild degradation was also seen in oxidative stress conditions and photolytic degradation, but the drug was stable to thermal stress. The method was validated for parameters like linearity, precision, accuracy, specificity, robustness and so forth. and was also applied to marketed samples. Thus, the method can be employed for analysis of drug during stability studies.

\section{References}

[1] USP DI, Advice for the Patient, Drug Information in Lay Language, vol. II, Micromedex, Ankeny, Iowa, USA, 19th edition, 1999.

[2] M. L. Constanzer, C. M. Chavez, and B. K. Matuszewski, "Low level determination of dorzolamide and its de-ethylated metabolite in human plasma by liquid chromatography with atmospheric pressure chemical ionization tandem mass spectrometry," Journal of Pharmaceutical and Biomedical Analysis, vol. 15, no. 7, pp. 1001-1008, 1997.

[3] A. Maltese and C. Bucolo, "Rapid high-performance liquid chromatographic assay of dorzolamide in rabbit aqueous humor," Biomedical Chromatography, vol. 16, no. 4, pp. 274276, 2002.

[4] R. C. Tim, R. A. Kautz, and B. L. Karger, "Ultratrace analysis of drugs in biological fluids using affinity probe capillary electrophoresis: analysis of dorzolamide with fluorescently labelled carbonic anhydrase," Electrophoresis, vol. 21, no. 1, pp. 220-226, 2000.

[5] A. Zammataro, R. Saletti, C. Civiale, V. Muccilli, V. Cunsolo, and S. Foti, "Simultaneous quantification of carteolol and dorzolamide in rabbit aqueous humor and ciliary body by liquid chromatography/atmospheric pressure chemical ionization mass spectrometry," Journal of Chromatography B, vol. 878, no. 9-10, pp. 807-814, 2010.

[6] A. Dovletoglou, S. M. Thomas, L. Berwick, D. K. Ellison, and P. C. Tway, "Development of practical HPLC methods for analysis and quality assessment of the novel carbonic anhydrase inhibitor MK-0507 and the acetamidosulfonamide intermediate," Journal of Liquid Chromatography, vol. 18, no. 12, pp. 2337-2352, 1995.

[7] N. Erk, "Rapid and sensitive HPLC method for the simultaneous determination of dorzolamide hydrochloride and timolol maleate in eye drops with diode-array and UV detection," Pharmazie, vol. 58, no. 7, pp. 491-493, 2003.

[8] R. Kanchan, S. M. N. Roy, and R. B. Rane, "Simultaneous RPHPLC determination of dorzolamide hydrochloride and timolol maleate in pharmaceutical preparations," Trade Science Inc., vol. 7, no. 8, 2008.

[9] T. J. Novak and L. Berwick, "Determination of the enantiomeric composition of a novel topically active carbonic anhydrase inhibitor by HPLC," Journal of Liquid Chromatography and Related Technologies, vol. 21, no. 12, pp. 1883-1896, 1998.

[10] L. I. Bebawy, "Application of TLC-densitometry, firstderivative UV-spectrophotometry and ratio derivative spectrophotometry for the determination of dorzolamide hydrochloride and timolol maleate," Journal of Pharmaceutical and Biomedical Analysis, vol. 27, no. 5, pp. 737-746, 2002. 
[11] N. Erk, "Simultaneous determination of dorzolamide HCL and timolol maleate in eye drops by two different spectroscopic methods," Journal of Pharmaceutical and Biomedical Analysis, vol. 28, no. 2, pp. 391-397, 2002.

[12] I. M. Palabiyik, M. G. Caglayan, and F. Onur, "Multivariate optimization and validation of a CE method for simultaneous analysis of dorzolamide hydrochloride and timolol maleate in ophthalmic solution," Chromatographia, vol. 73, no. 5-6, pp. 541-548, 2011.

[13] N. Erk, "Voltammetric and HPLC determination of dorzolamide hydrochloride in eye drops," Pharmazie, vol. 58, no. 12, pp. 870-873, 2003.

[14] S. Sağlik, "Determination of dorzolamide in ophthalmic solutions using solid-phase extraction by high-performance liquid chromatography," Acta Pharmaceutica Turcica, vol. 42, no. 2-3, pp. 98-100, 2000.

[15] H. M. Sharath, G. Jose, K. P. Channabasavaraj, and J. S. Modiya, "Development and validation of spectrophotometric methods for Estimation of dorzolamide HCL in bulk and pharmaceutical dosage forms," International Journal of Pharmaceutical Sciences and Research, vol. 2, no. 4, pp. 948-953, 2011.

[16] Code Q2A-Text on Validation of Analytical Procedure Step-3 Consensus Guideline, ICH Harmonised Tripartite Guideline, 1994.

[17] Code Q2B-Validation of Analytical Procedure Methodology Step-4 Consensus Guideline, ICH Harmonised Tripartite Guideline, 1994.

[18] Code Q2A-Text on Validation of Analytical Procedure Step-3 Consensus Guideline, ICH Harmonised Tripartite Guideline, 1994.

[19] Code Q2B-Validation of Analytical Procedure Methodology Step-4 Consensus Guideline, ICH Harmonised Tripartite Guideline, 1994. 


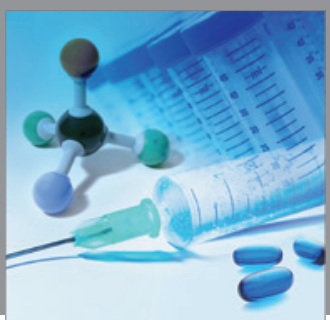

International Journal of

Medicinal Chemistry

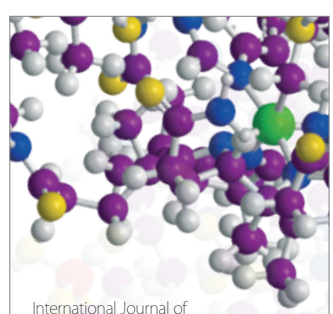

Carbohydrate Chemistry

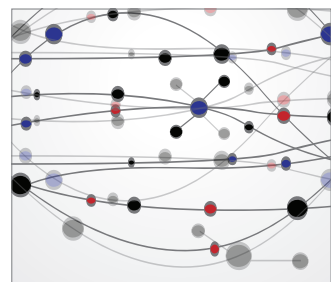

The Scientific World Journal
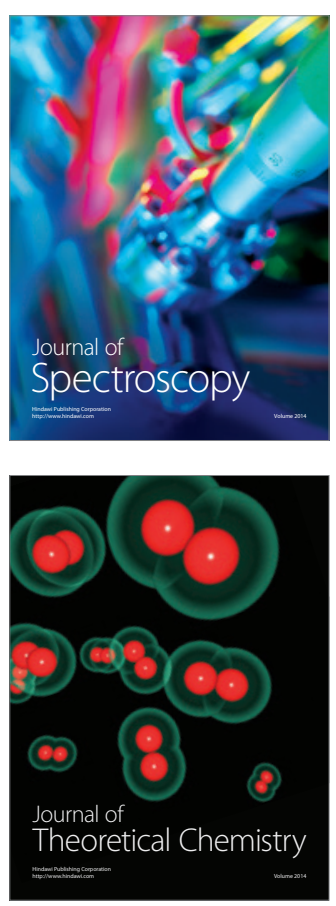
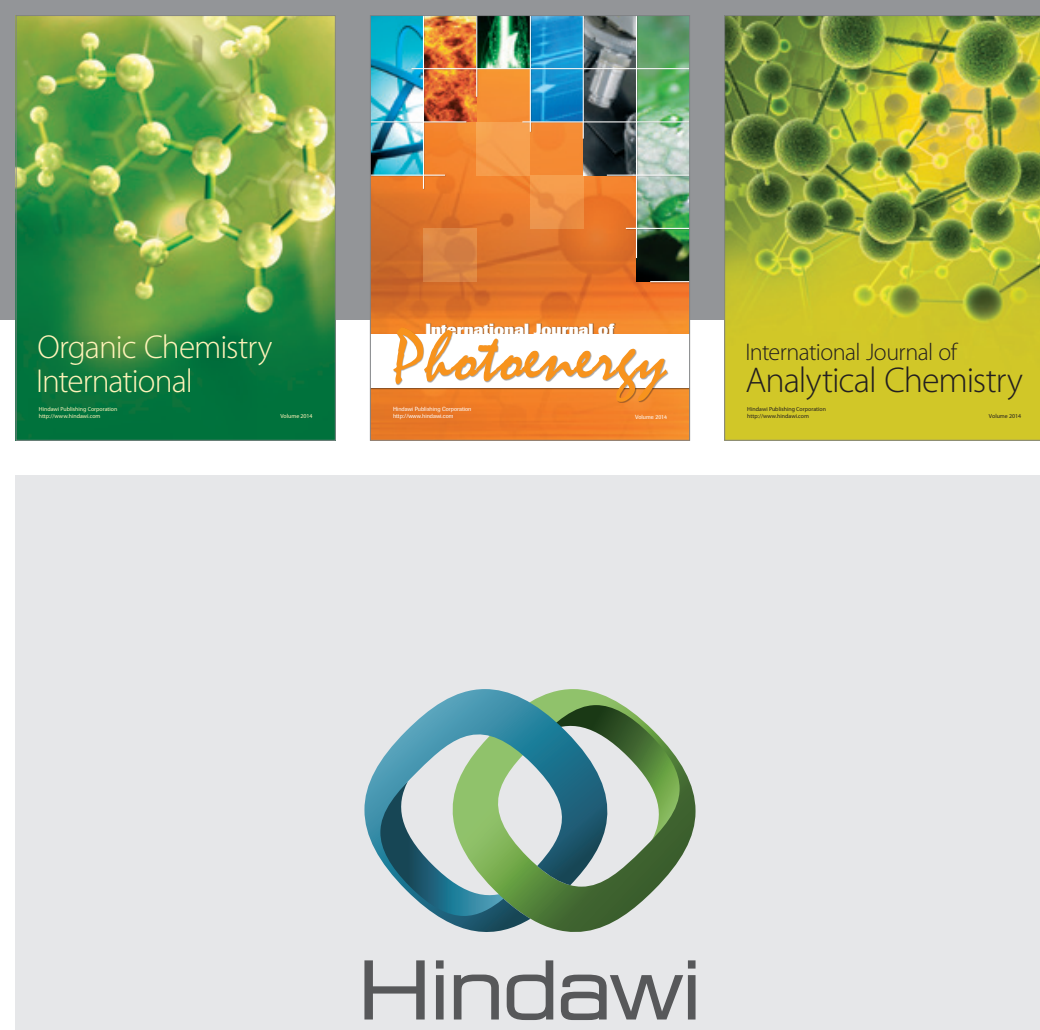

Submit your manuscripts at

http://www.hindawi.com
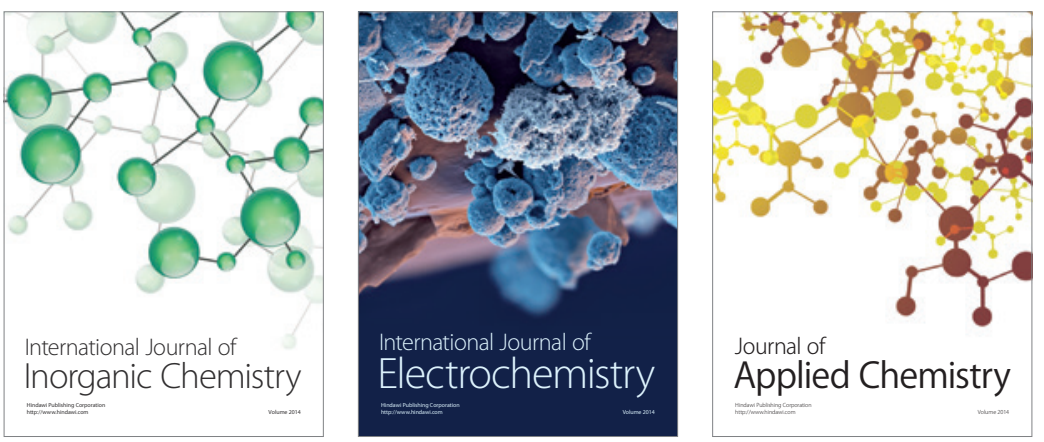

Journal of

Applied Chemistry
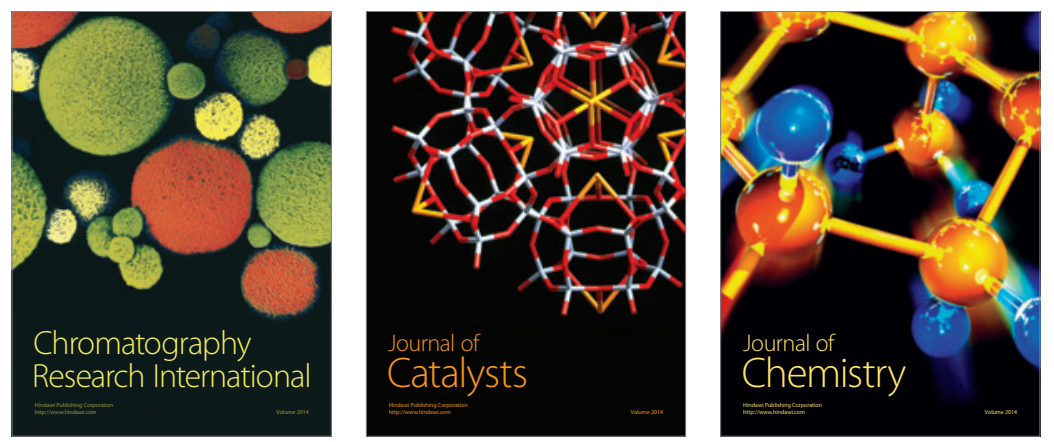
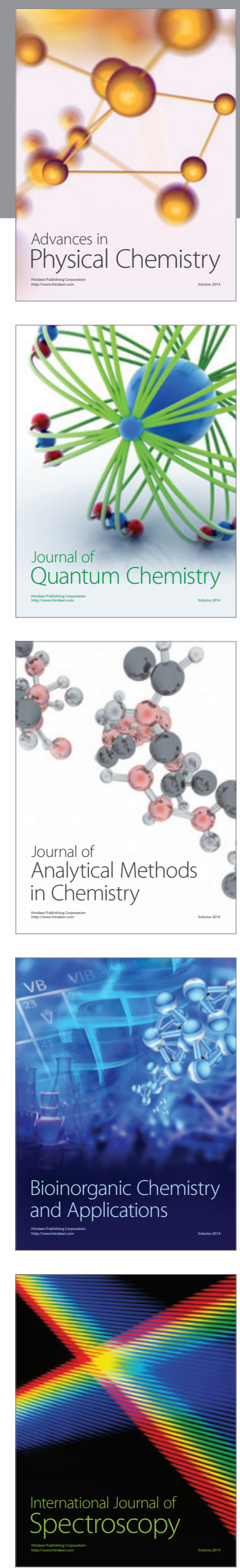